\title{
Design-based Evaluation: A Novel Evaluation Approach to Examine Designed Programs in Engineering Education
}

\section{Dr. Lori C. Bland, George Mason University}

Lori C. Bland, Ph.D., is an associate clinical professor of curriculum and research, and the Director of Curriculum, Center for Gifted Education at The College of William and Mary. She teaches courses in program evaluation, educational assessment, educational psychology, data-driven decision-making, and gifted education. Bland received her Ph.D. in Educational Psychology from the University of Virginia. Her current research focuses on assessing learning and professional outcomes in formal and informal STEM learning environments; how data are used to inform decision-making; and the uses of different research, evaluation, and assessment methods to solve educational problems.

\section{Dr. Margret Hjalmarson, George Mason University}

Margret Hjalmarson is a Professor in the Graduate School of Education at George Mason University. Her research interests include engineering education, mathematics education, faculty development and mathematics teacher leadership.

\section{Prof. Anastasia P. Samaras, George Mason University}

ANASTASIA P. SAMARAS is Professor of Education in the College of Education and Human Development at George Mason University, USA. She is an educational researcher and pedagogical scholar with signature work in self-study research methodology including co-editor of Polyvocal Professional Learning through Self-Study Research (2015) and author of Self-Study Teacher Research (2011) and lead editor of Learning Communities In Practice (2008). She is recipient of the Dissertation Research Award, University of Virginia, the Outstanding Scholar Award, University of Maryland, a Fulbright Scholar, and a Visiting Self-study Scholar. She served as chair of S-STEP from 2013-2015 and is a current Co-PI of two National Science Foundation (NSF) funded grants: Designing Teaching: Scaling up the SIMPLE Design Framework for Interactive Teaching Development and a research initiation grant: Student-directed differentiated learning in college-level engineering education. Her research centers on facilitating and studying her role in faculty development self-study collaboratives.

\section{Prof. Jill K. Nelson, George Mason University}

Jill Nelson is an associate professor in the Department of Electrical and Computer Engineering at George Mason University. She earned a BS in Electrical Engineering and a BA in Economics from Rice University in 1998. She attended the University of Illinois at Urbana-Champaign for graduate study, earning an MS and PhD in Electrical Engineering in 2001 and 2005, respectively. Dr. Nelson's research focus is in statistical signal processing, specifically detection and estimation for applications in target tracking and physical layer communications. Her work on target detection and tracking is funded by the Office of Naval Research. Dr. Nelson is a 2010 recipient of the NSF CAREER Award. She is a member of Phi Beta Kappa, Tau Beta Pi, Eta Kappa Nu, and the IEEE Signal Processing, Communications, and Education Societies. 


\title{
Design-based Evaluation as a Novel Evaluation Approach for Faculty Development Programs in Engineering Education
}

\author{
Introduction \\ In this theory paper, the authors introduce design-based evaluation (DBE) as a novel evaluation \\ approach for the engineering education research community. Many projects and programs in \\ engineering education focus on the creation of new models for teaching and learning that engage \\ students in active learning. As a result, engineering educators are simultaneously designing the \\ models and conducting research about the designs. Project evaluators face the challenge of how \\ to document the progress of such design-based research innovations at the same time as the \\ influence of the innovation on the learning environment is studied. We suggest design-based \\ evaluation as a companion framework for design-based research projects. In this paper, we \\ discuss the application of DBE to a faculty development program for STEM education.
}

In what follows, we provide the motivation and background for developing a new evaluation approach, design-based evaluation. We provide a brief description of design-based research to situate design-based evaluation. Next, we offer a discussion of the challenges in evaluating design-based research, which will be useful to others. We discuss a design-based faculty development research project as an example of the type of project that would benefit from DBE and discuss the challenges associated with evaluation of this project. Then, we discuss the limitations of extant evaluation approaches in terms of design-based research. Finally, we discuss the salient characteristics and elements of design-based evaluation.

\section{Motivation and Background}

The motivation and background for this theory paper is grounded within identifying an appropriate evaluation approach for a National Science Foundation funded design-based research faculty development project [1]. No extant approaches met the evaluation goals for the project. Therefore, we developed an evaluation approach to meet the needs of this design-based research project. In this paper, we extracted those characteristics and elements of design-based evaluation applicable to the evaluation of design-based research.

\section{What Do We Mean by the terms "Evaluation" and "Evaluation Approach?"}

The purpose for evaluation is to judge the merit or worth of a program. Evaluation is distinct from research and assessment. Each endeavor has a different purpose and poses different questions. This can be confusing because evaluations often use assessment and research results, in addition to evaluation results, in order to determine a project's merit. An evaluation approach acts as a guide for a given evaluation [2]. Evaluation is considered to be a transdisciplinary field [3]. However, evaluation approaches have developed distinct differences based on: (a) philosophical or ideological differences, such as those derived from a positivist versus a constructivist paradigm; (b) methodology, such as experimental, case-based, or policy-driven; and (c) disciplinary boundaries, such as education or social services [4]. Thus, the evaluation approach should align with the nature of the program, the purposes for the evaluation, the sensibilities of the program stakeholders and decision-makers, and the utility of the evaluation data. We developed an evaluation approach to guide our evaluation practice in examining the merit of a design-based research project because extant approaches were insufficient. 


\section{Characteristics of Design-based Research}

Design-based research (DBR) is a research methodology that arose from the learning sciences to examine innovative design in educational programs. The goal of DBR is to study learning and teaching at the intersection of design processes and research methods [5]. If one considers research methods as individual characteristics that exist on a continuum, then we can compare and contrast DBR to more traditional educational research based on where each type of research effort falls on the continuum.

One key characteristic is research design emphasis. Traditional research is designed for theorybuilding as its first priority. Application to real-world problems is derived from theory. In contrast, DBR is designed to solve real-world classroom problems as its first priority. Conjecture-building is derived from practice.

A second characteristic of DBR is the degree of dynamism within the research process. In traditional educational research, a hypothesis is tested, and an intervention is administered. The expectation is that neither the hypothesis nor the intervention will be changed over the course of the study. In contrast, because DBR is designed to solve real world problems, mutable conjectures about learning processes and outcomes are posited [6,7]. Conjectures and the instructional intervention adapt over the course of the study as actual learner processes and outcomes are revealed. Such changes allow the researcher to develop understanding of learning processes over time and provide faculty with the opportunity to improve the instruction for the learner.

These two characteristics imply that DBR must embrace emergent phenomenon in the research design as a third characteristic. In traditional research, learning is researched as a fixed outcome at the completion of an intervention. However, the goal of DBR is to capture the learners' evolving constructions of understanding and the corresponding instructional changes as adaptations for the learners. DBR must function as a creative research process. Therefore, DBR is an apt methodological stance for research in engineering education as design is a crucial process in solving real world engineering problems [8].

\section{Challenges in Evaluating Design-Based Research}

One challenge in evaluating DBR is unplanned, purposeful variation in design and implementation in order to understand learning processes. Program evaluation has focused on how a given educational intervention has solved an educational problem to produce specific learner outcomes. Interventions typically address the introduction of a new curriculum or program. Often the evaluation focus occurs at a macro or systemic level where the goal is to minimize variation in implementation. However, the focus of DBR is geared toward understanding learning and solving real world classroom problems. The evaluation focus for DBR occurs not at the macro level but at the micro, or individual, level and at the meso, or classroom, level, where addressing variation in learning and adapting to that learning variation with a re-envisioned intentional teaching design is critical. Thus, one key challenge in evaluating DBR is determining how one deals with unplanned, purposeful variation within an intervention that solves a real-world classroom problem as the teaching design changes across the program. For the evaluator, a main question is "What counts as fidelity of implementation?" 
The second challenge in evaluating DBR is dynamism in the research process. Most, though not all evaluation approaches, have been developed to examine an intervention that is administered as static, or fixed. Typically, educational interventions are developed in advance of implementation. In K-12, teachers receive professional development related to implementation of the intervention and new materials as a group. The new intervention is compared to "business as usual," or the current curriculum and instructional practices. As a result, the research design involves random assignment with a control or comparison group. Within higher education, students are often assigned randomly to classes with new instructional approaches and compared to control groups receiving traditional lecture-based instruction. However, this is not often practical within educational settings or for interventions that are still under development. Therefore, an entire classroom of students is typically assigned to the intervention, while a comparison group is typically assigned to the "business as usual" extant curriculum. The researcher often attempts to match the two groups of students based on demographic characteristics, such as socio-economic status, and individual characteristics, such as learning needs or ability. In addition, there are stages of research needed to design interventions before comparison to "business-as-usual." The evaluation of such research projects also follows a static evaluation design.

DBR is inherently about equity and attempting to figure out how all learners process information [9]. Therefore, instruction is adapted by the teacher within the context of examining student data and improving the instruction continuously using intentional design principles [6]. DBR research adapts to these changes. That is, the conjectures about learning adapt as does the intervention [6], [7]. Because DBR examines evolving instructional designs and is a dynamic research process, a second key challenge in evaluating DBR is determining how one deals with adaptive conjectures and research processes that are responsive to unplanned, purposeful variation in instruction [10]. The key evaluation question is, "What is the nature and level of adaptation within an evaluation of a DBR project?"

\section{Conceptual Framework: Adaptive Design as the Fulcrum for Change}

Within design-based research, instructional design that can be adapted to actual, rather than hypothesized, learning processes are keys to project success. Laurillard's [11] conception of teaching as a design science provided the conceptual framework: (a) teaching improvement should be encouraged; (b) improvement begins with self-reflection; (c) a teaching community supports change; (d) teaching change needs to be designed; (e) participating in a teaching community supports engagement with new teaching designs; and (f) teaching changes should be documented and shared [11]. In a non-judgmental teaching community, faculty can take risks, sharing successes and failures, receive constructive feedback, and build on each other's ideas. The design principles for this faculty development project were grounded within Laurillard's conceptual framework [1], [11]. Thus, adaptive design functioned as the fulcrum for change within our design-based research project, and its evaluation.

\section{The SIMPLE Project: Design-based Research on Faculty Development}

The faculty development project was developed and implemented as a design-based research project [12], [8]. One purpose for the project was to support and examine undergraduate STEM faculty change processes toward adopting and implementing interactive teaching strategies. A 
second purpose was to support and examine the nature of faculty discourse and self-study about their role and efforts in the interactive teaching strategies they enacted in their classrooms [13].

For this project, the high-level conjecture was that by participating in a supportive and collaborative teaching community, faculty will initiate small changes in their teaching which will lead to larger changes observed across a faculty development trajectory. The SIMPLE design principles grounded project implementation: (a) Sustainability (S) in the form of small, ongoing faculty groups; (b) Incremental change (I) as small, "doable" changes; (c) Mentoring (M) by faculty leaders who have been using interactive teaching strategies and are willing to talk about their successes and failures to model a realistic improvement process; (d) People-driven (P) by allowing each individual and group to address their own needs and interests; (e) Learning environment (L) creation for interactive teaching; and (f) Design -- faculty document their teaching changes within a design memo for their reflection and for other faculty [14].

The project included four types of faculty groups. Each group applied the SIMPLE principles in a design that worked for the group. The design was adapted to address participant needs and group changes over the course of the project. The faculty research group consisted of the principal investigators (who represented engineering, science, education, research methods, and STEM educational research), the graduate research assistant (a mathematics educator), and the evaluator. The faculty leadership group included the faculty research group and the STEM discipline-based faculty leaders for each of the teaching development groups (TDGs). The TDGs were discipline-based faculty peer groups supporting each other in their use of interactive teaching strategies. The teaching inquiry group (TIG) consisted of faculty who were interested in conducting and publishing a self-study of their teaching processes [15].

\section{Challenges in Evaluating this Faculty Development Project}

Evaluating the grant posed multiple challenges which were discussed in other papers [10], [16], [17]. One key challenge was the people-driven nature of the project. Applying the people-driven SIMPLE principle implied that faculty decision-making structured the choice of an interactive teaching strategy, its implementation, and the nature of each faculty member's participation in their TDG. Each individual faculty member chose a different interactive teaching strategy. Even if chosen strategies were similar, faculty implemented the strategies differently. Faculty created multiple, different interventions for their classes. This research design was in contrast to an approach where instructors are assigned to an intervention or a control/comparison group to implement a common teaching strategy [14], [13].

A second challenge was how group decision-making within each discipline-based TDG shaped that faculty learning community [18]. For example, the structure and implementation of group processes, such as frequency and characteristics of meetings, the readings for and activities within meetings, and the voluntary nature of group membership were decided upon by each individual group. Each faculty learning community was structured differently. This was in contrast to a standard intervention/control or comparison group regulating meeting structure and content.

A third challenge was that the research focused on understanding the processes of faculty development, rather than the outcomes of faculty development. Traditional research typically 
focuses on assessing faculty or student outcomes. In addition, evaluation stages typically employ a formative stage in which instructional processes are examined to determine fidelity of implementation and a summative stage in which instructional outcomes are examined to determine the degree to which the intervention was successful. In this study, processes were examined throughout the project. Examining change processes without examining student outcomes is difficult because the expectation is that the process itself is not as important as demonstrating an outcome for students.

A fourth challenge was the learner (faculty)-driven nature of the project within different STEM disciplines. The underlying common denominator was decision-making about self-change. Thus, uncovering the change processes for each individual faculty member was, necessarily, a need for the evaluation in order to determine whether there were commonalities in barriers or affordances for change, commonalities in decision-making, commonalities in how faculty thought about and implemented change initially and over time. Finding the commonalities was important for illustrating whether the project could be implemented elsewhere, with the identified affordances and with barriers minimized.

Overall, there was a great deal of variation designed into the project. These were issues because evaluators want to control variation in order to examine fidelity of implementation and to determine treatment effects. Therefore, we focused on the salient principles of the project to develop an evaluation design that would reflect the design-based nature of the research within the faculty learning communities, and the learner-driven actions of individual faculty. We found that extant evaluation approaches were insufficient for capturing the complexity of individual processes.

\section{Limitations of Extant Evaluation Approaches for our Design-based Research}

At the beginning of the faculty development study, the project evaluator applied elements of practical-participatory evaluation (PPE) [19]. The reason for applying the PPE approach was that the evaluator met regularly with the PIs, as well as attended group leader meetings and the meetings of the TIG group. Thus, multiple stakeholders had the opportunity to provide input and feedback throughout the entire project cycle directly to the evaluator. The project evaluator also applied elements of utilization-focused evaluation [20]. The purpose for applying a utilizationfocused approach (UFA) was to inform decision making for appropriate stakeholders, such as the researcher team, the group leaders, and the faculty participants. The UFA ensured that the key stakeholders, the principal investigators, were regularly receiving information that could inform their practice, especially given the level of participant involvement. In addition, the project evaluator also applied the CIPP model (context, input, process, and product) [21]. CIPP supported the examination of the overall context for learning, the inputs related to faculty learning, and the processes to support faculty learning. Thus, these approaches initially were helpful to support the principal investigators (PI) use of formative evaluation results to make decisions for a process-oriented project. Further, the project evaluator had considered applying a developmental evaluation (DE) approach because of the dynamism and adaptation occurring within the project [22].

The limitations of each evaluation approach became readily apparent. For example, one problem with UFA in this project was that the contexts for the interventions varied. In addition, there 
were multiple decision-makers, which included each of the faculty participants. While the PIs made some of the decisions, the people-driven principle supported individual faculty decisionmaking based on their own needs.

A problem with PPE was that communication with participants and socially constructed knowledge were important for some of the formative aspects of the evaluation. However, PPE could not address the summative collective and cumulative learning of the research team and group leaders. For example, PPE could not support our explanations about how project elements could be implemented more widely within politically charged institutions of higher education.

The evaluator applied CIPP to focus on implementation processes, which was helpful for formative decision-making for the PIs. However, this faculty development project focused on the faculty development trajectory in applying interactive instruction. CIPP did not address individual learning processes and barriers and successes for faculty development trajectories, which was the primary focus for this project.

DE was not appropriate for this project, despite the dynamism and adaptation. At its heart, DE is an evaluation stage [22]. The dynamism was not a stage in this project implementation. It was a defining characteristic of the project in terms of adherence to the SIMPLE principles. Adherence to these principles were key to fidelity of implementation. Therefore, the dynamism was a necessary condition for the project and should not change based on the stage of the project.

While elements of each of these approaches were helpful to evaluate this project, neither individual evaluation approaches, nor the approaches in combination addressed all of the critical elements of the project as a gestalt. Thus, this cobbling together of evaluation approaches were initially acceptable but were not going to be successful over the length of the project.

Extant evaluation approaches did not capture the elements of this design-based research project because of the underlying assumptions of this project and its design. One conjecture was that faculty would design their own learning trajectory. A second conjecture was that faculty processes and outcomes would necessarily vary. The evaluated study was intentionally designed to allow for, and indeed encourage, variation in both the processes evaluated and faculty outcomes. More specifically, there was variation within the program design that encouraged variation within site implementation. The project intention was to study the nature of the variation within the faculty change processes, faculty learning about and through the change process, and the unique types of outcomes attained by faculty. No extant approach could address intentional variation in design and implementation, nor the dynamism in the research process. Thus, the evaluation approach for the grant developed into a novel approach, which we have termed design-based evaluation (DBE) as an evaluation approach to align with design-based research.

\section{What is Design-based Evaluation?}

Design-based evaluation is an evaluation approach that examines the adaptability and implementation of the conjectures, design, and mediating processes that produce developmental trajectories of outcomes within innovative learning programs. The purpose for DBE is to identify the affordances and barriers of change and unique variations within a DBR project that 
contributed to change. Design-based evaluation is based on the tenets of DBR. First, like DBR, $\mathrm{DBE}$ focuses on innovative educational programs. Innovation is key. These are programs that are different, that do not focus on tweaking a norm, but on changing the norm and on remaining innovative for the life of the program. Second, DBE is grounded within the learning sciences to evaluate the program design and how different components of the design contribute to outcomes as elucidated by the conjectures. Third, DBE focuses on the learning and teaching processes and how they mediate outcomes throughout the course of the entire evaluation. Fourth, DBE examines learning trajectories. That is, DBE accounts for the phenomenon of proximal and medial processes as outcomes for one or more participant groups. Fifth, like DBR, DBE juxtaposes multiple competing processes. For example, DBE applies dynamic design resulting from creative problem-solving in the field.

The focus for DBE is to help program officers develop understanding about the effectiveness of the processes that contributed to learning for continuous, real-time program improvement. The DBE focus is in contrast to the evaluative activity as primarily judging program worth based on mistakes in implementation, insufficient resources, or lack of expected outcomes. DBR intentionally situates these competing processes within the design of programs to focus on learning. This means that teaching is intentionally designed to be supportive of the desired learning processes and outcomes. The processes and products of learning are equally important.

Within DBE, mistakes, resource issues, and lack of expected outcomes are considered to be acceptable variation within real-world scenarios. In DBE, such instances are not used to judge the merit or worth of the program. Rather, they are used by program evaluators and implementers to consider how to adapt teaching processes. For example, in this faculty development program, faculty documented their interactive teaching designs in a design memo. The design memo also included lessons learned and suggestions for other faculty who might want to implement the strategy. In the design memo, faculty openly discussed successes and challenges/mistakes. A critical component was understanding the processes used by faculty in documenting their design, as well as the processes used by the teaching development groups to provide a safe environment for faculty self-evaluation and discourse. Mistakes were considered to be an acceptable part of the learning process, rather than a violation of fidelity of implementation.

Aspects of the program were evaluated based on adherence to the overall design principles, such as on the degree to which: (a) issues were documented; (b) issues were addressed in a manner that contributed to faculty learning about interactive teaching, and (c) faculty responses to the process and their reflection on their teaching change. Thus, DBR and DBE are complementary processes. While each have distinct questions related to the distinct nature of each different inquiry, they are mutually informative in modeling how and why the program worked to create participant learning trajectories.

\section{The Bricolage: Design-based Evaluation Elements}

Our design-based evaluation approach aligned to the nature of DBR. One key element of DBE was the main focus on program design principles. Thus, in this faculty development project, the SIMPLE principles were used to examine fidelity of implementation as the underlying framework for the project. DBE allowed us to document change processes, mediators, and 
interactions within and across the change processes [17]. DBE provided a structure to meaningfully examine the anticipated and unexpected change processes, effects, and outcomes. DBE provided an evaluative means to accept each unexpected event as a learning event within the faculty development program. The unanticipated became a strategy for further use or a justin-time program improvement. Thus, DBE provided a means to simultaneously examine the unique trajectories of the research and learning communities, as well as the personalized learning trajectories for each faculty member within each of those communities [16].

A second key element of DBE was that it provided the means to consider the unique situativity of each learning event $[23,24]$. The evaluation endeavor focused on documenting implementation change and variation across learner processes and outcomes. DBE addressed the situated nature of learning within each of the faculty communities and how faculty communities enacted the design principles within a given STEM department. The barriers and affordances for learning and change were examined by individual, faculty community, and department. Thus, considering situativity encouraged a positive disposition about environmental and implementation change and variation, rather than considering that implementation fidelity was problematic in a given environment.

A third element of DBE was a focus on the people-driven principle. DBE accounted for distinct categories of individualized, learner-driven outcomes. This DBE element is in contrast to an examination of mean and standard deviation for a given outcome. We could examine a larger set of group outcomes based on individualized outcomes [25]. Importantly, this element of DBE also provided a lens to examine research group learning [17]. Thus, fidelity of implementation focused on the broader design-based principles underlying the project at all levels of the project, research group, group leaders, teaching development groups, teaching inquiry groups, and individuals [4].

A fourth element of DBE was the use of conjecture maps to illustrate program enactment. Conjecture maps can be used in conjunction with or in place of logic models, as the pictorial representation of program theory. A conjecture map is a tool grounded in design-based research methods to understand learning. Conjecture maps represented the project design in terms of conjectures about how the program worked, and depicted the embodiment of the design (tools, materials, participant and task structures, and discursive practices), mediating processes, and outcomes. In an earlier study, we found that conjecture maps were useful tools to examine adaptation and provided more useful information than our logic model [16], [17],[26]. The conjecture maps were used to show changes over time as related to the conjectures, implementation, or outcomes. In addition, conjecture maps were useful for studying iterations in the design process as the innovation was tested in different settings.

For this project, the evaluator generated conjecture maps over the course of the project and conducted focus group interviews with the principal investigators to determine how well the conjecture maps represented the project. This feedback process elicited the investigators' thinking about the project and the design process. The conjecture maps captured the principal investigators' preliminary theories about how the groups would work and reflections about their work as it was operationalized in practice. By using the conjecture maps, we found that the overarching goals of the project were supporting faculty learning about interactive teaching 
within the TDGs and TIG, but different department conditions and interests created different types of group interactions and functioning. Thus, we were able to understand the causes of the variation that occurred in response to the needs of the different TDGs, and as situated within their departments and colleges. Figure 1 is an example of one of our conjecture maps created during the project [18].

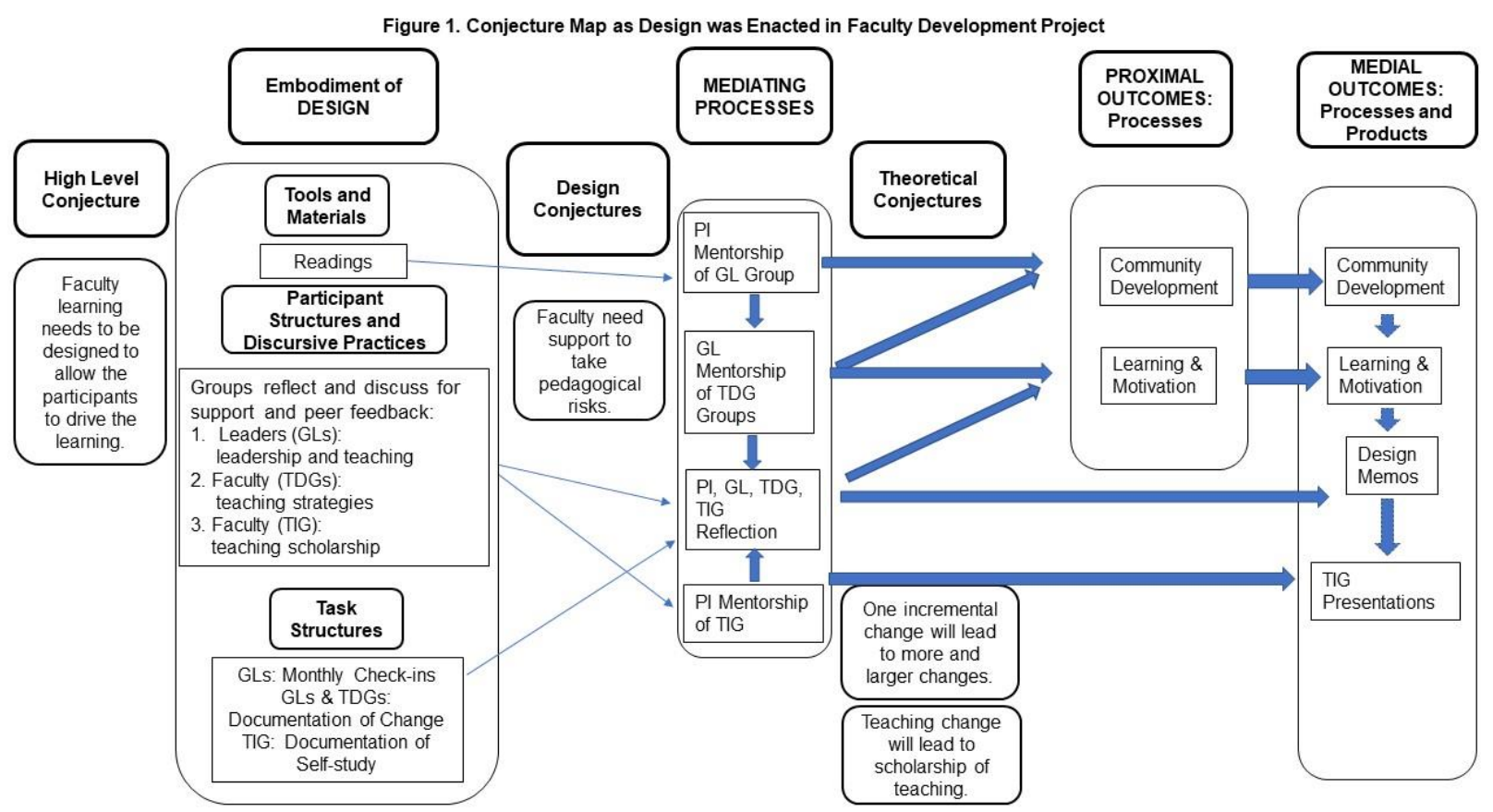

A fifth element of DBE is that program theory and evaluation methods must adapt to incremental findings. Adaptation in DBE is similar to adaptation in DBR. That is, research conjectures and program implementation change in response to dynamic changes in learning processes resulting from evaluative findings. DBE provided a means to address researcher and group leader learning and the resultant project or group adaptations. Thus, DBE must operate as adaptable to researchers and to how implementation, processes, and outcomes can be examined. Changes over time in conjecture maps can be used to illustrate the adaptability.

\section{The Role of the Evaluator in DBE}

As in many evaluation approaches, the role of the evaluator within DBE is to act as a "critical friend" [27]. The evaluator's actions should model evaluative thinking by asking questions, being accepting of participants' comments, engaging all stakeholder groups, reflecting on discussions, and deriving themes for consideration by the participants and principal investigators. A second role of the evaluator is to provide data for decision-making within the project, for program development, and for further research. A third role is to act as a sounding board for interpreting the evaluative data, specifically as applied to the conjectures about the nature of learning and whether the nature of the intervention needs to be adapted. A fourth role is for the evaluator to document the nature of program and participant evolution, including the situativity of the program components and participant actions that were effective, and those that were less effective. A fifth role of the evaluator for DBE is to act as a model of DBE. That is, the evaluator must model flexibility and open-mindedness to the changes that occur within the design of the 
study. Specifically, the evaluator needs to develop an internal understanding, as well as, with the researches and the stakeholders that the validity of the study is grounded within the dynamic evaluation of the adaptations that support learning.

In this faculty development project, the evaluator, acted as a "critical friend" in group leader and researcher meetings. In this role, the evaluator synthesized the themes in the discussion and reflected those themes back to the group for consideration and feedback. Specifically, the evaluator reflected faculty learning successes, even as faculty often only considered the learning challenges. The evaluator participated as a member of the research team, providing input about design changes. Because the evaluation approach itself was evolving, the design-based researchers also participated in a 360 process with the evaluator. Within engineering and STEM education, the evaluator must also demonstrate adaptive expertise, self-monitoring, and employ agile and novel research and evaluation processes [28].

\section{Other Applications for DBE}

DBE can act as an effective evaluation approach to support DBR in formal or informal learning engineering education environments. For example, DBE is an ideal approach for faculty development of interactive teaching strategies and the study of the effects of those strategies within the formal engineering program when the conjectures about teaching and learning processes and student outcomes are dynamic. DBE is also ideal for engineering education because of the need for students to integrate technical knowledge, design, experimentation, and problem-solving with professional skills within formal learning environments, whether face-toface or online. DBE provides the structure to examine student skills integration within these different learning environments. The evaluator can then provide the appropriate feedback for researchers to design and develop subsequent iterations of the programs based on how students processed knowledge and demonstrated the applied skills. DBE is an ideal evaluation approach for co-curricular opportunities, such as service learning or engineering competitions or in informal settings, such as voluntary hackathons. For example, research in different types of learning environments have produced different outcomes across the ABET standards [29], [30]. Thus, the nature of problem-based or project-based learning as designed implies the need to examine the conjectures and learning activities as situated within the given environment in order to determine the critical elements of learning and the processes that worked in these informal environments.

\section{Uniqueness of DBE as an Approach}

DBE is a unique evaluation approach as it was developed to address programs within the learning sciences and design-based research programs. DBE as an evaluation approach is learner-driven, that is, it is designed to follow the trajectory of the learner, even if there are unanticipated variations in program processes and implementation or variations in learner outcome types. Further, variation in implementation is considered to be important in order to maintain the learner-driven nature of the approach. DBE can be used to illustrate the change process on a developmental trajectory of process as proximal or medial outcomes [16]. This implies that one function of DBE is to model organic change within a program related to changes in conjectures over time, degree of adaptation across program implementation, and the evolution of developmental learning processes. Formative evaluation may allow for minor changes to implementation but not to hypotheses, change theory, or in measuring expected outcomes in 
traditional evaluation. However, DBE follows adaptations resulting from DBR and examines the resultant outcomes. While adaptation is seen as positive, DBE would also indicate whether the adaptations did not have the anticipated effect. While traditional evaluation would expect conformity to one process, the goal in DBE is to understand what the variation was, the conditions under which it occurred, and the reasons for why the variation worked, allowing an understanding of the situativity of affordances and barriers to change.

DBE focuses on design principles in addressing individual needs. For example, DBE addresses individual learner changes, with documentation for each of the changes. As in traditional research, DBE does not attempt to examine the average of the changes. Rather, DBE provides a focus on commonalities and differences. The documentation of the changes in this faculty development study created the range of possibilities for what to expect within a faculty developmental trajectory. The most important contribution of the use of conjecture maps within DBE was to model change in our study. The conjecture maps illustrated the nature of processes developing into incremental outcomes; that is, change processes were both proximal and medial outcomes. This finding illustrated the dynamic, informal, and organic nature of the how the design elements were enacted within the project both within and across groups [17]. A principal feature of design science is expected adaption [5], [31]. DBE not only allows for the adaptation but also highlights that adaptation as a key process, as fidelity of implementation, and as a proximal or medial outcome on a developmental trajectory.

\section{Conclusion}

DBE functions at the juxtaposition of multiple processes to make known the changes in conjectures, program implementation, and unplanned, purposeful variation. DBE captures the dynamism expected from DBR research. In addition, DBE allows for capturing the design process, rather than only the final product, in order to inform the design of similar innovations. DBE fills a gap within the evaluation approach repertoire, as evidenced by the fact that applying standard evaluation approaches did not fully address the rich learning experiences in this faculty development program. Further, DBE can be used to assist with programs that may not be at the stage where comparative methods are appropriate or may have more complex outcomes than a standardized test. Applying approaches that fit only standard programs is insufficient for the world of learning that has opened with co-curricular experience, active learning, interactive teaching, computerized adaptive learning, maker-spaces, and design-based experiences. DBE can be used to address the broad range of learning experienced across the lifespan of the learner in both informal and formal learning environments.

This project was supported by the National Science Foundation under Grant No. DUE \#1347675 and Grant No. EEC \#1424444. Any opinion, findings, and conclusions or recommendations expressed in this material are those of the authors and do not necessarily reflect the views of the National Science Foundation. 


\section{References}

1 Hjalmarson, M. A., \& Nelson, J. K. (2014). Creating small interactive teaching groups. Proceedings of the 121st ASEE Annual Conference. Indianapolis, IN.

2 Shadish, W. R. 1998. Evaluation theory is who we are. American Journal of Evaluation, 19(1): 1-19.

3 Scriven, M. (2008). The concept of a transdiscipline: And of evaluation as a transdiscipline. Journal of MultiDisciplinary Evaluation, 5(10): 65-66.

4 Fitzpatrick, J. L., Sanders, J. R., \& Worthen, B. R. (2011). Program evaluation: Alternative approaches and practical guidelines ( ${ }^{\text {th }}$ ed.). Boston: Pearson.

5 Kelly, A. E., Baek, J. Y., Lesh, R. A., Bannan-Ritland, B. (2008). Enabling innovations in education and systematizing their impact. In: A. E. Kelly, R. A. Lesh, \& J. Y. Baek (Eds.). Handbook of design research methods in education: Innovations in science, technology, engineering, and mathematics learning and teaching, pp. 3-18. New York: Routledge.

6 Anderson, T., \& Shattuck, J. (2012). Design-based research: A decade of progress in education research? Educational Researcher, 41(1), 16-25. https://doi.org/10.3102/0013189X11428813

7 Sandoval, W. A. (2014) Conjecture mapping: An approach to systematic educational design Research. Journal of the Learning Sciences, 23,1, 18-36. doi:10.1080/10508406.2013.778204

8 Hjalmarson, M. A., \& Lesh, R. A. (2008). Engineering and design research: Intersections for education research and design. In: A. E. Kelly, R. A. Lesh, \& J. Y. Baek (Eds.). Handbook of design research methods in education: Innovations in science, technology, engineering, and mathematics learning and teaching, pp. 96-110. New York: Routledge.

9 Confrey, J. \& Lachance, A. (2000). Transformative teaching experiments through conjecturedriven research design. In A. E. Kelly \& R. A. Lesh (Eds.). Handbook of research design in mathematics and science education. pp. 231-266. New York: Routledge.

10 Bland, L. C., Nelson, J., Hjalmarson, M., \& Samaras, A. (2017, June). Applying Conjecture Mapping as a Design-Based Research Method to Examine the Design and Implementation of a Teaching Development Project for STEM Faculty. Proceedings of the American Society for Engineering Education Annual Conference \& Exposition, Columbus, $\mathrm{OH}$. https://peer.asee.org/27602

11 Laurillard, D. (2012). Teaching as a design science: Building pedagogical patterns for learning and technology. New York: Routledge.

12 Kelly, A.E. (2003). Research as design: The role of design in educational research. Educational Researcher, 32, 304.

13 Samaras, A., Hjalmarson, M., Nelson, J., Bland, L. C., Nelson, J. K., \& Christopher, E. K. (in press). Self-Study as a Method for Engaging STEM Faculty in Transformative Change to Improve Teaching. International Journal of Teaching and Learning in Higher Education, $31(2)$.

14 Nelson, J. K., \& Hjalmarson, M., \& Bland, L. C., \& Samaras, A. P. (2016, June). SIMPLE Design Framework for Teaching Development across STEM. Proceedings of the American Society for Engineering Education Annual Conference \& Exposition, New Orleans, Louisiana. doi:10.18260/p.26187

15 Nord, J., Samaras, A., Ericson, R., Ikonomidou, V., Rytikova, I., Sachs, R., Schwebach, J. R., Nelson, J., \& Gerasimova, D. (2016, Fall). Teaching as a creative and learning process. 
Presentation at the Innovations in Teaching and Learning Conference, George Mason University, VA.

16 Bland, L. C. (2017, March). Faculty Development as Process: Perils in Evaluation. American Society for Engineering Education Zone 2 Annual Conference, San Juan, Puerto Rico.

17 Bland, L. C., Hjalmarson, M., Nelson, J., \& Samaras, A. (2018, June). To map or to model: Evaluating dynamism in organically evolving faculty development. Proceedings of the American Society for Engineering Education Annual Conference \& Exposition, Salt Lake City, UT.

18 Gerasimova, D., Nelson, J., Hjalmarson, M., Bland, L. C., \& Samaras, A. (2017, April) Faculty learning communities as a means of fostering interactive teaching: Broadening or deepening? Paper presented at the annual meeting of the American Educational Research Association, San Antonio, TX.

19 Cousins, J. B., \& Earl, L. M. (1992). The case for participatory evaluation. Educational Evaluation and Policy Analysis, 14, 397-418.

20 Patton, M. Q. (2008). Utilization-focused evaluation, $\left(4^{\text {th }} \mathrm{ed}\right)$. Thousand Oaks, CA: Sage.

21 Stufflebeam, D. L., \& Coryn, C. (2005). Evaluation theory, models, \& applications, (2 ${ }^{\text {nd }}$ ed.). San Francisco: Jossey-Bass.

22 Patton, M. Q. (2010). Developmental evaluation: Applying complexity concepts to enhance innovation and use. New York: Guilford.

23 Johri, A., \& Olds, B. M. (2011). Situated Engineering Learning: Bridging Engineering Education Research and the Learning Sciences. Journal of Engineering Education, 100: 151185. doi:10.1002/j.2168-9830.2011.tb00007.x

24 Johri, A., Olds, B. M., \& O'Connor, K. (2014). Situative Frameworks for Engineering Learning Research. In A. Johri \& B. M. Olds (Eds.), Cambridge Handbook of Engineering Education.

25 Bland, L. C. (2019). Assessing Learner-driven Constructs in Informal Learning Environments: Synergies Created by the Nexus of Psychometrics, Learning Analytics, and Educational Data Mining. MARCES Book Series. Data Analytics and Psychometrics: Informing Assessment Practices (pp.129-176). Charlotte, NC: Information Age Publishing.

26 Sandoval, W. A. (2004). Developing learning theory by refining conjectures embodied in educational designs. Educational Psychologist, 39, 213-223. doi:10.1207/s15326985ep3904_3

27 Rallis, S. F. and Rossman, G. B. (2000), Dialogue for learning: Evaluator as critical friend. New Directions for Evaluation, 2000: 81-92. doi:10.1002/ev.1174

28 McKenna, A.F. (2007). An Investigation of Adaptive Expertise and Transfer of Design Process Knowledge. ASME. Journal of Mechanical Design, 129(7):730-734. doi:10.1115/1.2722316.

29 Pierrakos, O., Borrego, M., \& Lo, J. (2008, June). Assessing students' learning outcomes during summer undergraduate research experiences. Paper presented at the 2008 ASEE Annual Conference and Exposition, Pittsburg, PA.

30 Pierrakos, O., \& Trenor, J. (2009, June). Using A Mixed Methods Approach To Investigate Students' Perceived Learning And Challenges Faced During A Summer Undergraduate Research Experience. Paper presented at the 2009 Annual Conference \& Exposition, Austin, Texas. https://peer.asee.org/4963 
31 Kelly, A. E. (2014). Design-based research in engineering education: Current state and next steps. In A. Johri \& B. M. Olds (Eds.), Cambridge handbook of engineering education research (pp. 497-418). New York: Cambridge University Press. 